\title{
Crisis Communication Failure: A Case Study of Typhoon Morakot
}

\author{
Shuhui Sophy Cheng ${ }^{1}$ \\ ${ }^{1}$ Department of Communication Arts, Chaoyang University of Technology, Taiwan \\ Correspondence: Shuhui Sophy Cheng, Department of Communication Arts, Chaoyang University of \\ Technology, 168 Jifeng E. Rd., Wufeng District, Taichung 41349, Taiwan. Tel: 886-4-2332-3000. E-mail: \\ sophy@cyut.edu.tw
}

Received: December 10, $2012 \quad$ Accepted: January 11, $2013 \quad$ Online Published: February 28, 2013
$\begin{aligned} & \text { doi:10.5539/ass.v9n3p18 } \\ & \text { URL: http://dx.doi.org/10.5539/ass.v9n3p18 }\end{aligned}$

\begin{abstract}
In 2009, Typhoon Morakot was the deadliest typhoon to impact Taiwan in recorded history. Around 700 people were either killed or lost in the catastrophe, while damage to agricultural, public construction and business losses amounted to NT $\$ 110$ billion (US\$3.5 billion). The purpose of this study is to examine the crisis with Typhoon Morakot and how governmental agencies respond to the needs of the citizens. Throughout the stages, three main themes of Taiwanese government's response to Typhoon Morakot emerged: 1) ignoring the warning signs in pre-crisis stage, 2) failure in crisis response in crisis stage, and 3) taking corrective actions in post-crisis stage. The findings demonstrate a need to develop culturally and ethnically competent crisis response to minority population. It is important to note that the necessity of community participation during reconstruction is essential.
\end{abstract}

Keywords: Typhoon Morakot, crisis communication, crisis leadership, best practices in crisis communication

\section{Introduction}

Taiwan is no stranger to natural disasters, having experienced earthquakes, typhoons, floods, and landslides every year. Typhoon Morakot in 2009, however, was the deadliest typhoon to impact Taiwan in recorded history. It hit the island on August 8, 2009, dropping three meters of rain on the southern areas in three days. The heavy rainfall led to severe flooding and massive mudslides. Around 700 people were either killed or lost in the catastrophe, while damage to agricultural, public construction and business losses amounted to NT\$110 billion (US\$3.5 billion). It appeared that the Taiwanese government was ill prepared for the Typhoon Morakot, since many residents were not evacuated successfully. Even though the heavy rainfall caused the disaster, management of the crisis and communications were slow and poorly coordinated at all levels of government which only highlighted the government's weaknesses. Typhoon Morakot exposed significant flaws in the government's preparedness for catastrophic disasters and the capacity to respond to them.

Consequently, President Ma and his administration faced enormous criticism and were blamed by the disaster victims. The government's poor crisis response became the focus of intense public and media criticism. In particular, this typhoon disaster showed the importance of effective crisis communication to the public. The public demanded to know what happened before, and during the crisis, and who should be held accountable in the aftermath of crisis.

Researchers have extensively examined crisis communication from both the organizational and political perspective for over the last two decades (Benoit, 1995; Coombs, 2007; Seeger, Sellnow, \& Ulmer, 2003). However, crises as a result of natural disasters have received less systematic attention (Sellnow, Seeger, \& Ulmer, 2002). Moreover, there are fewer published cases and analyses of crisis communication among government agencies and political representatives than there are in a corporate/business context (Avery \& Lariscy, 2010). This study is an attempt to fill that gap. Given the scale of natural disasters, many individuals deem the government as a responsible party and tend to blame the government for failing to provide adequate protection against a natural disaster (Abney \& Hill, 1966). Typhoon Morakot provided a unique opportunity for studying the role that communication plays in a government's effectiveness in responding to disaster. The purpose of this study is to examine the crisis with Typhoon Morakot and how governmental agencies respond to the needs of the citizens. Most importantly, this article addresses the lessons the Taiwanese government should have learned from Typhoon Morakot and how to prevent the same issues in another natural catastrophe. 


\section{Literature Review}

\subsection{Crisis Communication}

Coombs (2007) defines a crisis is "the perception of an unpredictable event that threatens important expectancies of stakeholders and can seriously impact an organization's performance and generate negative outcomes" (p. 2). As crisis is an unexpected event, it creates the need to respond to stakeholders through communication. Scholars have long recognized the important role that communication plays in effective crisis management. Fearn-Banks (2010) defines crisis communication as "the dialog between the organization and its public prior to, during, and after the negative occurrence. The dialog details strategies and tactics are designed to minimize damage to the image of the organization" (p. 2). Moreover, crisis communication is concerned with the transferring of information to significant persons to help avoid or prevent a crisis, recover from a crisis, and maintain or enhance reputation (Fearn-Banks, 2010). Crisis communication, as Seeger and Ulmer (2002) note "concerns the processes whereby organizations create and exchange meanings among stakeholders regarding the risk of crisis, cause, blame, responsibility, precautionary norms, and crisis-induced changes in the organization and its relationship to stakeholders" (p. 128). Practically speaking, four general consistent communication demands of crisis are prevalent: managing uncertainty, responding to crisis, resolving the crisis, and learning from the crisis (Ulmer, Sellnow, \& Seeger, 2007). Managing uncertainty might need a consistent voice in the form of a spokesperson who can maintain the flow of information. Responding the crisis is to maintain openness to reduce uncertainty. Resolving the crisis requires specific actions to offset the harm. Finally, learning from the crisis helps leaders to learn lessons about how to avoid repeating mistakes and enhance prevention.

Crisis communication literature has examined catastrophic natural disasters, such as hurricanes (Gallagher, Fontenot, \& Boyle, 2007; Garnett \& Kouzmin, 2007), tsunamis (Perry, 2007), floods (Sellnow, Seeger, \& Ulmer, 2002), forest wildfire (Avery \& Lariscy, 2010), and earthquakes (Ho \& Hallahan, 2004). Littlefield and Quenette (2007) indicate that "a natural disaster illustrates a time when the public is uncertain about what will happen, confused about what to do, and disoriented by the accompanying chaos" (p. 29). Lerbinger (1997) has noted: "disasters caused by nature are considered 'acts of God' because they are generally uncontrollable and the public tends to accept them fatalistically" (p. 57). However, Comfort (1989) argues that natural disasters interact with human structures and processes in highly complex and unpredictable ways that often intensify harm. Furthermore, natural disasters "present an extraordinarily difficult context for inter-organizational and inter-jurisdictional coordination. When disaster threatens a community, it requires different responses from different organizations at different locations to set aside prior activities and focus time, effort, and attention on a common goal" (Comfort, Sungu, Johnson, \& Dunn, 2001, p. 145). Accordingly, Lerbinger (1997) proposes that emergency management planning and the adequacy of the response are important elements in natural disasters.

In the existing literature, Coombs (2007) indicates that the three-stage model (pre-crisis, crisis, and post-crisis) can be applied as macrostages to many models of crisis response. Coombs (2009) defines the first stage, the pre-crisis stage, as "actions organizations take before a crisis ever occurs" (p. 100). Pre-crisis stage involves prevention and preparation, which seeks to reduce known risks that could lead to a crisis. Thus, it is essential to develop a system for detecting potential crisis and take all possible actions to prevent crises. The second crisis stage begins with the trigger event and marks the onset of the crisis, continuing until the organization returns to some sense of normalcy. Within this period, it is often accompanied by extreme emotional turmoil, high uncertainty, and intense confusion. Coombs (2007) reveals communication with stakeholders is a critical facet of this stage. Organizations need to respond to the crisis, offering explanations about the cause, blame, responsibility, and consequence. The final post-crisis stage involves undertaking steps to correct what went wrong, identify responsible parties, and determine what should be done to prevent and prepare for the next crisis. During the post-crisis period, the organization needs to gather data from the crisis follow up communication with stakeholders and continue monitoring potential risk factors related to the crisis.

The three-stage model of crisis management -- the most widely accepted model today in crisis communication literature -- is not associated with any particular theorists, but has been recommended by a variety of crisis communication experts (Coombs, 2007; Seeger, Sellnow, \& Ulmer, 2003). This model "is grounded in the crisis-related communication activities that organizations undertake at particular times as they face particular contingencies" (Seeger, Sellnow, \& Ulmer, 2003, p. 103). In essence, the three-stage model can provide a framework to understand the type of crisis and media coverage of the event in the wake of Typhoon Morakot.

\subsection{Crisis Leadership}

When a natural disaster occurs, people tend to look to government as a responsible party (Abney \& Hill, 1966). It's because people deem the government shall take the proper measures to prevent, mitigate the damage, and 
respond to aid recovery. Given the above, the victims might seek to assign blame when things go wrong, even in the event of an uncontrollable natural disaster. Specifically, Littlefield and Quenette (2007) argue that "those in authority must display crisis leadership to reestablish order and confidence" as disasters move through pre-crisis, crisis and post-crisis stages (p. 30). Seeger, Sellnow, and Ulmer (2003) propose general guidelines for effective crisis leadership in terms of both form and content. Form recommendations concern what a leader should do after a crisis and content refers to the actual response the leader provides following a crisis. Illustrations of effective crisis leadership include to being visible, open and honest; cooperating with others; working to build a reservoir of goodwill, exploring opportunities for renewal; and adapting their leadership styles and contingencies during crises (Ulmer, Sellnow, \& Seeger, 2007, p. 61).

For instance, expressing concern for victims and visiting the scene of the event is often identified as a basic leader response to a crisis (Coombs, 1999). Active attention of the leader may provide comfort and reassurance to those affected, help reconstitute a sense of normalcy, and help leverage resources for mitigation. A crisis role model valuable to government officials is former New York City Mayor, Rudolph Giuliani. Giuliani's presence, fast action, compassion drew people to him for information, support and understanding during September 11 terrorist attacks in 2001. Pinsdorf (2004) highlights that Giuliani "was just about flawless in his reactions after September 11, a textbook how-to-do handling of the situation" (p. 22).

In contrast, Mayor Ray Nagin showed little ability to lead the city of New Orleans during Hurricane Katrina in 2005. He was criticized because "the city lacked a coordinated plan to help victims find shelter, and lacked communication infrastructures by which citizens could request help, and report dire and emerging consequences of the storm's damage" (Waymer \& Heath, 2007, p. 92). He failed to declare a mandatory evacuation until 19 hours before Hurricane Katrina hit the city. The delayed mandatory evacuation seemed to send a message to the residents that their local government leader was not aware the threat of the hurricane, so neither should they. Although $90 \%$ of the residents were eventually evacuated, those who remained were the poor, disable and elderly. In the wake of a natural disaster, the nation was shocked by the devastation and destruction caused by Hurricane Katrina. In a broader context, the effective crisis leadership might create an opportunity; however, ineffective crisis leadership might make a crisis much worse.

\subsection{Best Practices in Crisis Communication}

Supported by the National Center for Food Protection and Defense (NCFPD) and National Science Foundation (NSF), a group of crisis and risk communication experts in the United States conducted research on a large sample of crisis cases. Seeger (2006) synthesizes the results into a set of ten general best practices (BP) for effective crisis communication. The best crisis communication practices outlined below originated from the research literature and the advice of subject-matter experts, with a focus primarily on widespread public crisis or disaster.

BP 1. Coordinating process approaches and policy development

BP 2. Conducting pre-event planning

BP 3. Developing partnerships with the public

BP 4. Listening to the public's concerns and working to understand the audience

BP 5. Designing messages and delivering the messages with honesty, candor, and openness

BP 6. Collaborating and coordinating with credible sources

BP 7. Meeting the needs of the media and remain accessible

BP 8. Communicating with compassion, concern, and empathy

BP 9. Accepting uncertainty and ambiguity

BP 10. Disseminating message of self-efficacy

According to Seeger (2006), "communication strategies should be fully integrated into the decision-making process" (p. 236). Dozier and Broom (1995) also agrees that it is most effective when communication functions cooperatively as part of the policy formation process. Moreover, a crisis plan should be developed before a crisis. A crisis plan can serve as a constant reminder of potential problems and enhance overall mindfulness regarding risks. As suggested by Seeger (2006), an effective plan must include instructions on how to monitor potential problems, clarify responsibilities and decision-making structures, and identify communication channels to reach different audiences. An organization should acknowledge the uncertainty and ambiguity when information is not available. The over-reassuring statements may reduce a spokesperson' credibility if found to be inaccurate. 
When an organization uses a dialogic approach to reach out to the public and offers up-to-day information, the public can serve as a resource and a legitimate partner in crisis management (Seeger, 2006). The public, in essence, becomes part of the decision-making process. From this perspective, an organization needs to make an effort to understand the needs of its audience and to respond to them in a timely manner. It is important for the crisis responder to be honest, candid, open and accountable with their communication. These qualities will encourage the public to start a dialogue with the organization. Most importantly, "honesty in the long run, fosters credibility with both the media and the public" (Seeger, 2006, p. 239). In addition, an expression of compassion, concern, and empathy can enhance the credibility and perceived legitimacy of messages during a crisis.

During a crisis, collaborating with credible sources increases the credibility of the organization. Moreover, "these collaborative relationships allow agencies to coordinate their messages and activities" (Seeger, 2006, p. 240). Another best practice requires communicators to engage the media, and use the media as the conduit to the public. Thus, messages of "self-efficacy can help restore some sense of control over an uncertain and threatening situation" (Seeger, 2006, p. 242).

Best practices in crisis communication can be carried out during any stage of a crisis. According to Reynolds (2006), "the concept of best practices for crisis communication is a valuable foundational approach that can help guide organizations before, during, and following a crisis event" (p. 249). Venette (2006) agrees that "best practices represent the concerted efforts of communication scholars to improve communication among experts, emergency responders, and various publics" (p. 230). Littlefield and Cowden (2006) tested best practices with three underrepresented cultural groups and concluded that half of the recommendations are receiver-centered (meet the needs of media and remain accessible, communicate with compassion, demonstrate honesty, accept uncertainty, provide messages that foster self-efficacy) and half are sender, or organization-centered (crisis communication is an on-going process, conduct pre-crisis planning, listen to public's concerns, foster partnerships with public, collaborate and coordinate with credible sources).

In many professional disciplines, a best practice is a method or technique that becomes the industry standard and is used as a benchmark. Specifically, best practices approach is a form of grounded theory for an organization that evolves and becomes better. Moreover, "best practices can also be understood as larger lessons for organizational and professional learning for a particular venue of practice" (Seeger, 2006, p. 233). The best practices have been illustrated and expanded in numerous other publications (e.g., Sellnow, Seeger, \& Littlefield, 2009; Veil, Buehner, \& Palenchar, 2011). This study thus also aims to expand on existing theory to advance our understanding of best practices in crisis communication in a non-Western context.

The following three research questions are proposed based on the previous theoretical discussion and literature review.

RQ1: How did the governmental agencies respond to the needs of citizens during Typhoon Morakot?

RQ2: How did President Ma react to criticism of the central government's response to Typhoon Morakot in his speeches?

RQ3: Based on best practices in crisis communication, what lessons should the Taiwanese government learn from Typhoon Morakot?

\section{Method}

As a case analysis, this study is qualitative in nature. The research design is based on a case study methodology combining rhetorical criticism with crisis communication theory. The data were collected from a variety of sources, including the official website of Executive Yuan and office of President, Nexis-Lexis, Google search engine and relevant websites that reported and discussed typhoon Morakot. In this study, the primary data included: 1) government documents and publications (e.g., government information, statements, press releases, archival records, and reports); 2) speeches (e.g., interviews and speeches of President Ma Ying-jeou). The media articles represented the secondary data. To undergird the analysis, the media coverage (e.g., daily newspaper and broadcast transcripts) within and outside of Taiwan were reviewed. The analysis of Typhoon Morakot in this study included two press releases from Office of President, two speeches from broadcast interview, one television transcript and 23 newspaper articles from daily news sources in and outside of Taiwan. The period of analysis covered a twelve-month period, starting on August 6, 2009, the day of news about the land warning for Typhoon Morakot, and ending on August 8, 2010, the first anniversary of the disaster.

After the data were collected from multiple sources, a detailed timeline of relevant events leading up to the crisis itself and the post-crisis process was created. A narrative description and process analysis of the event were thus constructed. As noted earlier, this study examines the crisis surrounding Typhoon Morakot and how the 
governmental agencies responded to the needs of its citizens. In doing so, this case study extends the application of the three-stage model of crisis and best practice in crisis communication (Seeger, 2006) to the public sector. Each stage appears to involve relatively distinct kinds of communication activities. Therefore, a stage-by-stage analysis is preferable for evaluating the crisis response from the government agencies.

The procedures for analysis involved three steps. First, in the pre-crisis stage, this study examined what happened when Typhoon Morakot was approaching Taiwan. Second, in the crisis stage, the analysis investigated the officials' coordination of resources and collaboration after Typhoon Morakot made landfall. Third, a review of officials' crisis response during the crisis and post-crisis was presented. Subsequently, implications for lessons learned from this case study were provided.

Drawing from Braun and Clarke's (2006) thematic analysis procedures, this study used their techniques to identify recurring themes and salient issues found within the case. It was chosen because it is a flexible method for "identifying, describing, analyzing and reporting themes and patterns within data" (Braun \& Clarke, 2006, p. 79). Moreover, thematic analysis emphasizes the relationship between themes and research questions and the ability of themes to entail essential elements of the data. The identified themes of Taiwanese government's crisis response follow.

\section{Findings}

\subsection{RQ1: Taiwanese Government's Response to Typhoon Morakot}

In the past, the vast majority of scholarly work examining crisis communication has focused on prevention, response, and recovery stages. For instance, it is widely accepted that NASA's communication failures in the warning stage led to the Challenger explosion in 1986 (Marshall, 1986). Response is perhaps the most critical of the three stages identified in crisis communication research (Hale, Dulek, \& Hale, 2005). Key stakeholders are targeted in the crisis response stage, and a dialogue with these stakeholders is developed. In the final phase of the model, the recovery stage, the organization focuses its efforts on reputation management and returning the organization to a sense of normalcy. Drawing from this framework, the analysis of Morakot focused on planning and communication prior to the arrival of the typhoon, the response during the crisis, and the reaction following the disaster. Throughout the stages, three main themes of Taiwanese government's response to Typhoon Morakot emerged from this case: 1) ignoring the warning signs in pre-crisis stage, 2) failure in crisis response in crisis stage, and 3) taking corrective actions in post crisis stage.

\subsubsection{Ignoring the Warning Signs in Pre-crisis Stage}

Pre-crisis is often associated with a failure to receive or attend to a threat signal or message (Seeger, Sellnow, \& Ulmer, 2003). On August 6, 2009, Central Weather Bureau (CWB) issued a land warning for Typhoon Morakot. They warned residents in the north and northeast that the storm was packing powerful winds and torrential rain. Moreover, they cautioned residents in mountain areas to be aware of the possibility of landslides. On August 7, 2009, all local governments declared a typhoon day - closing schools and offices and cancelling flights as the typhoon approached the island. During the day, the CWB said Typhoon Morakot slowed as it approached the nation's east coast. As the Pacific high air pressure guiding Typhoon Morakot's movement weakened, the typhoon appeared to linger in one place. Meanwhile, CNN meteorologist Kevin Corriveau predicted that the impact of Typhoon Morakot on Taiwan would be massive. He said that "the island tends to prepare well for typhoons; they take it very seriously, just like Cuba is very good at handling hurricanes. Taiwan is very good at handling typhoons" (Typhoon Morakot nears Taiwan, 2009). However, Corriveau was wrong this time.

Generally speaking, regions of the country that regularly experience severe weather routinely have employed methods to prevent disaster and warning through local or state emergency management offices to increase preparation (Reynolds \& Seeger, 2005). These typically include encouraging residents to stockpile supplies, such as water, food, flashlights, and evacuating in the cases of an extreme typhoon threat. However, information from the time the typhoon hit indicated that the CWB initially warned of the potential for extensive damage caused by strong winds and torrential rains in northern Taiwan and predicted low rainfalls for the south. They did not know the typhoon would bring the usual annual rainfall in the south in just three days. When rains started falling hard, the bureau steadily upgraded its rainfall forecast. The CWB changed its predictions many times. Ultimately, it dumped far more rainfall (three meters of rain) on Taiwan than the bureau predicted. The residents in the southern areas were confused and frustrated by the inaccuracies communicated by the CWB. More specifically, this discrepancy between the predictions and what was experienced created great uncertainty for them. Since then, CWB received severe public criticism for not providing accurate forecasts of the strength of the typhoon and the areas it would hit. 
To complicate things further, the central government had not reacted promptly enough to alert southern local officials to evacuate residents. Fink (1986) suggests that during pre-crisis stage, an official should detect early warning signs (prodromes) of a crisis because the assumption for a decision-maker within an organization is to acknowledge "that a crisis looms on the horizon" (p. 1). In the face of Typhoon Morakot, many local authorities lacked a sense of crisis and failed to take measures for a forced evacuation of people living in danger areas. Cole and Fellows (2008) indicate that the lack of motivation of evacuation "may be attributed to inconsistent and/or lack of messages from disaster officials and spokespersons (e.g., mayor, governor) and lack of spokesperson credibility" (p. 220). In the early stage of Typhoon Morakot weather monitoring, officials provided conflicting messages regarding the volume of rainfall. As Typhoon Morakot moved closer, the risk of heavy rain to individuals living in the southern regions did not effectively reach all audiences. If the government could have caught the significant warning signs of potential danger, the damage of Typhoon Morakot might be minimized.

\subsubsection{Failure in Crisis Response in Crisis Stage}

Different communication exigencies and audiences emerge in the crisis stages. An immediate audience of those affected by the crisis may include victims, close family members, emergency workers and first responders. Typhoon Morakot survivors blamed the central government for its failure to launch rescue and relief operations within 72 hours of the disaster - a critical period that provided the best chance of rescuing victims. Communication efforts during the crisis stage may involve dissemination of information regarding evacuation orders, scope of the harm, sheltering in place, medical treatment, and the like. Moreover, the crisis response should be proactive, accurate and responsive with stakeholders. The central government did not order immediate rescue operations or mobilize the necessary resources and manpower. Accordingly, the Ministry of National Defense was blamed for not sending out troops promptly. Since the military have the best training to meet all kinds of emergencies in the provision of large-scale humanitarian assistance and disaster relief, the armed forces should be quickly dispatched to the stricken areas when disaster strikes. Instead, the troops dragged its feet initially, with soldiers complaining about having to wait for orders even though time was of the essence (Ho, 2009).

A further source of public anger was the Ministry of Foreign Affairs' (MOFA) initial decision to refuse overseas aid in the first few days after the typhoon - a move blamed for the delay in the rescue operations. MOFA issued instructions on August 11,2009, to all overseas representative offices to decline their host governments if they offered material assistance and rescue teams to help Taiwan (Hsu, 2009). Deputy Minister Andrew Hsia claimed that the blunder was carelessness, not a mistake and said:

The memo dealt with instructing foreign countries how to donate money for relief efforts. Perhaps it was a technical error on our part, but we should have phrased the memo in such a way that it said that we were only 'temporarily' declining donations of goods and rescue workers. (Hsu \& Wang, 2009, p. 1)

On August 18, 2009, Hsia offered to resign amid intense criticism of his ministry response to the international aid. The central government later announced an embarrassing U-turn to accept foreign aid after insisting Taiwan did not need it. While MOFA took responsibility for the aid fiasco, it also defended itself by saying the Ministry was awaiting clarification from the Central Disaster Emergency Operation Center before requesting foreign assistance. This showed the government was bureaucratic and unresponsive during the crisis phase.

Journalist Chung (2009) argued that inappropriate remarks and performances by key senior officials created a negative impression and added to the growing public disappointment towards the government. For example, Hsueh Hsiang-chuan, Secretary-General of Executive Yuan, became the target of public criticism after saying on call-in television news show that there was nothing wrong with him having dinner with his father-in-law on August 8 - the day Typhoon Morakot slammed into Taiwan. Instead of taking responsibility for the government's response, his initial defensive remarks were: "Give me a break, it was Father's Day" (Chung, 2009. p. 4). Similarly, Premier Liu Chao-shiuan, was criticized for going to have his hair dyed and chatting at the barber shop on August 11, while rescue efforts were still underway in the badly stricken southern counties (Kao, 2009).

\subsubsection{Taking Corrective Actions in Post-crisis Stage}

A typhoon occurs quickly but the fallout of the incident may take months or years to repair and for recovery. Communication in post-crisis involves adjusting to new normality and resuming operations as usual. In many stances, post-crisis is also a period when the media and the public become more critical and questions are directed toward seeking the cause of the crisis, assigning blame, and learning preventative measures. In the post-crisis stage of Morakot, most attempts to assign blame focused on the president Ma's administration for handling the typhoon. 
President Ma's administration eventually took corrective actions after the scope of the disaster became clear. The military deployed 182,000 soldiers to evacuate thousands from the worst-hit areas, helped search for survivors and cleaned up the debris (Ma Ying-jeou's Katrina Moment, 2009). The government also did an about-face on aid and 59 countries contributed to relief including the acceptance of a U.S. offer of supplies and heavy-lift helicopters that could take earthmovers into remote areas (Adams, 2009). The government also announced a special budget of NT $\$ 100$ billion (US\$3.5 billion) for typhoon relief and reconstruction work during the next three years.

Since receiving harsh criticism over his administration's sluggish response to the disaster, President Ma made more than 60 trips to disaster zones and met with surviving victims on numerous occasions to hear their opinions about how to improve Taiwan's disaster prevention and response mechanism (Wu, 2009a). Moreover, a major Cabinet reshuffle was carried out to restore the government's tarnished image. As noted earlier, Deputy Foreign Minister Andrew Hsia offered to resign because his ministry rejected international aid. Two other senior officials, Defense Minister Chen Chao-min and Cabinet Secretary-General Hsueh Hsiang-chuan also submitted their resignations on August 19, 2009. Hsieh had been heavily criticized for leaving the Central Emergency Operation Center for a Father's Day dinner on August 8 when southern Taiwan was being pummeled by torrential rains from Typhoon Morakot. Chen was slammed for not dispatching soldiers in time and the military's seemingly lack of preparedness when faced with the natural disaster (Wu, 2009b). Premier Liu Chao-shiuan announced his resignation on September 7, 2009, as well. Personnel changes were made to punish negligence. However, the reconstruction work and recovery efforts would take years.

\subsection{RQ2: President Ma' Response to Criticism}

In the face of the devastation caused by Morakot, there was ample blame to go around. From government officials to lawmakers and local elected representatives, everyone pointed the finger of blame at others. It appeared that the rescue operations from all levels of government were far too slow and poorly coordinated. President Ma convened a national security meeting to coordinate the response of all government agencies on August 14, 2009, almost a week after Typhoon Morakot hit. A lack of trust in officialdom thus triggered public anger. Not surprisingly, President Ma came under particular attack for the central government's inadequate and slow response. A TVBS News poll reported that President Ma's approval rating in the aftermath of the typhoon plummeted to 16 percent in mid-August 2009, compared with to an all-time high of 79 percent in the days after his election victory in March, 2008 (Ko, 2009a).

The president also came under fire for being unsympathetic towards typhoon victims. When President Ma listened to a weeping villager who described himself as a supporter complained about how difficult it was to meet him, President Ma appeared visibly irritated and impatient to answer "Am I not here now" (Ho, 2009). Rather than expressing empathy and compassion for the victims, President Ma communicated aloofness and did not project himself as a leader who felt his people's pain. Ironically, in a news release from Office of President, President Ma said that "everyone involved in the rescue, relief and reconstruction effort must put themselves in the shoes of those who have been impacted by the disaster and strive to understand the pain and suffering currently being felt by those in the disaster areas" (Office of the President, 2009a).

The public's fury grew when President Ma appeared to blame the victims during an interview on Britain's Independent Television News (ITN). He claimed, "They were not fully prepared. If they were, they should have been evacuated much earlier. They didn't realize how serious the disaster was" (Enav, 2009). He seemed to criticize the victims by "insisting on staying rather than evacuating" (Shen, 2009). He also referred to disaster victims as "they" six times in answering the question. The local media, China Times, lambasted the president for his remarks, saying they were badly out of place. "It is not presidential to tell international media that the blame falls on people who would not evacuate in order to safeguard their own homes" (Enav, 2009).

Foreign critics said Typhoon Morakot was President Ma Ying-jeou's Hurricane Katrina (Ma Ying-jeou's Katrina Moment, 2009; Adams, 2009). Former U.S. president George W. Bush's cold response and apathy after Hurricane Katrina in 2005 was widely criticized and the concern he voiced later was unable to repair his image (A president far from his people, 2009). In both cases, the presidents were seen as slow to respond and disconnected from the people, especially the victims. President Bush was on vacation in Texas when the storm hit New Orleans. He was criticized for not being aware of looming disaster. He was also blamed for not being sensitive to those who run out food and water in the Superdome complex. Prior to the events of Typhoon Morakot, President Ma was generally seen as a charismatic leader that citizens would place their confidence during external threat. However, there were growing doubts over President Ma's ability to handle the typhoon crisis. The typhoon raised serious questions about President Ma's leadership. 
President Ma is not known as a good communicator. The New York Times described him: "Harvard-educated and prone to wonkish utterances ... His wooden qualities have been thrown into stark relief in recent days as he has tried to console storm victims" (Jacobs, 2009). Seeger (2006) explains that officials may refrain from expressing empathy or caring out of fear they will appear unprofessional but "these efforts to maintain professionalism are often perceived by the public to be cold and uncaring" (p. 241). In an effort to boost his image, President Ma made many trips to the affected communities afterwards. During memorial services, he prayed at the altar of the deceased and offered his condolences to the survivors. He expressed his regret in a caring and humble voice by making a long bow to them-a gesture of respect for the victims.

Moreover, President Ma tried to repair his image by offering an official apology for being "too slow and too disorderly" and not doing a "better and faster" job in a foreign news conference on August 18, 2009 (Office of President, 2009b). In an interview with CNN, he said, "Certainly, I will take full responsibility whatever the blame is because, after all, I am the President of this country" (Taiwan's leader takes blame for typhoon response, 2009). The President told CNN that heavy rains grounded rescue helicopters in the first few days after the storm hit, delaying relief. Specifically, he defended the actions of his government highlighting that the strength of the typhoon was completely unexpected. As a result, delays in aid were caused by the impossibility of rescue helicopters being able to take off. Moreover, he claimed "We will find out not only to correct the mistakes but [also] to punish the people responsible" (Taiwan's leader takes blame for typhoon response, 2009). To defend his crisis leadership ability, he said "I have exercised strong leadership throughout this process by ordering the armed forces to increase their participation in the disaster rescue operation ... At this critical moment, I must shoulder the responsibility for relocation and resettlement of the victims and I cannot escape my duties" (Chung, 2009). A series of polls conducted on the eve of his second anniversary of inauguration in May, 2010, revealed his popularity at around 40 percent. It showed a comeback from the rock bottom of 16 percent when he managed the Typhoon Morakot disaster in August, 2009 (Voters don't realize the good work Liu Chao-shiuan has done, 2010).

\subsection{RQ3: Lessons Learned from Typhoon Morakot}

Typhoons happen all the time in Taiwan. If we learn any lessons from the previous crisis events, we do not learn them well. President Ma called Typhoon Morakot a "painful lesson" (Typhoon Morakot was painful lesson, 2009). The analysis presented above makes several important points for crisis communicators. The following key lessons from Typhoon Morakot, which specifically apply to best practices in crisis communication, will enhance a greater understanding of how to plan for and respond to typhoons in the future. This analysis also ties its findings to the larger body of existing work and suggests other strategies for ensuring more effective crisis communication.

\subsubsection{Lesson One: Conducting Pre-event Planning and Coordinating Process Approaches and Policy} Development

Crisis does not occur in a vacuum. Fink (1986) proclaims that all crises have warning signs or prodromes, which indicate that a situation has the potential to develop into a crisis. Finding problems in the prodromal stage, before they turn into full-blown crisis can reduce the organizational harm and damage of reputation. Coombs (2007) notes that a crisis can be prevented if appropriate action is taken in response to the warning signs. In order to prepare for the unknown, or the pre-crisis phase, communication scholars advocate that organizations conduct crisis planning (Seeger, Sellnow, \& Ulmer, 2003; Coombs, 2009). Crisis planning "involves projecting the condition of a crisis and identifying the resources, structures, and strategies necessary to resolve the crisis with as little disruption, cost, and harm as possible" (Seeger, Sellnow, \& Ulmer, 2003, p. 163). Coombs (2009) purports that organizations create a Crisis Management Plan (CMP), or "a rough guide on how to prepare for crisis" in the pre-crisis stage (p. 101). Moreover, Fearn-Banks (2010) describes a Crisis Communication Plan (CCP) as "providing a functionally collective brain for all persons involved in a crisis, persons who may not operate at normal capacity due to the shock or emotions or the crisis event" (p. 7). Consistent with this idea, it is through the planning and preparation efforts at all levels of government that a crisis response mechanism can work effectively and efficiently.

Typhoons are frequent in Taiwan between July and September. Mother Nature reminds us that we live in a disaster-prone land and face drastic climate change. Prevention and preparedness are two components of the pre-crisis stage due to the nature of an increasingly technological society (Perrow, 1999). The question is whether the government is fully aware of this situation. Despite the billions of taxpayer dollars spent every year on emergency preparedness, gaps still remain in government strategy for handling natural disaster. The biggest tragedy of the Typhoon Morakot flood was that many of the devastations and causalities were the result of 
Taiwan's long-time negligence of land preservation (Reshuffling the cabinet is not enough, 2009). The impact of de-forestation, water diversion and other projects had affected the environment and possibly worsened the effects of mudslides and flooding. In the long run, development policy should take into account the risks of over-building and/or mismanaging natural land structure that will aggravate soil instability.

Typhoon Morakot revealed that the emergency relief mechanism was dysfunctional. In the future, the national response plans to strengthen coordination among central and local emergency need to be implemented. In the central government, the Central Disaster Emergency Center (CDEC) was established in 2006, which is the central coordinator in the event of disasters. The CDEC was created with the same mission as the America's Federal Emergency Management Agency (FEMA), but Taiwan still lacks the "standby preparedness" of FEMA (Taiwan needs to create its own FEMA, 2009). For example, FEMA has full time employees and volunteers always on reserve and works in partnership with U.S. state governments as well as private organizations such as the Red Cross. It is necessary to strengthen the function and the role of CDEC as a relief command center. CDEC needs to hone disaster response strategies and update overall operational mechanism to avoid similar mistakes. More importantly, drills should be routine so that the public can become aware and know what to prepare and what to do in an emergency.

\subsubsection{Lesson Two: Meeting Needs and Accessible to the Public}

In the face of Typhoon Morakot, media outlets, rather than governmental agencies, were the first to report the damage and the need for food in the stricken regions. The officials between the central and the local governments engaged in a process of blaming each other rather than attending to the immediate needs and monitoring the situation. Although there were government disaster prevention centers at both the national and local levels, people were forced to rely on TV talk show call-in lines instead of the government's rescue hotlines (Typhoon highlights old inefficiencies, 2009). Damages escalated as more victims called for help, which did not come in time. Under such circumstances, the media and the public often become more aggressive in their efforts to access information. As a best practice, it is essential for the government to meet the informational need of the public so that it can "build trust and promote a sense of collaboration and risk partnership" (Sellnow, Ulmer, Seeger, \& Littlefield, 2009, p. 28).

The public still prefers traditional media and considers them reliable sources (Seo, Kim, \& Yang, 2009). As a result, remaining accessible to media outlets is vital. In the pre-crisis stage, spokespersons should be appointed to disseminate accurate messages continuously with media. On the other hand, the government should establish a 24-hour call center and post daily briefings on its web site documenting its progress. Given the social media's contemporary pervasiveness, the government may incorporate social media tools to listen to crisis bearer concerns and engage in daily communication activities (Veil, Buehner, \& Palenchar, 2011).

In a sense, it is important to maintain honest and open communication with the public when disseminating information (Sellnow, Ulmer, Seeger, \& Littlefield, 2009). The Taiwanese government failed to manage its crisis communication from the beginning, by communicating in a proactive manner. The crisis had clearly exposed poor communication between the central and local governments. People in natural disaster require a steady stream of communication. Poor forecasting and inadequate communications before the onslaught of Typhoon Morakot gave residents little time to prepare and evacuate from the hardest-hit areas.

\subsubsection{Lesson Three: Collaborating and Coordinating with Credible Sources}

In addition to crisis planning, another relevant lesson in crisis communication is collaboration and coordination to assist in the establishment of partnerships. President Ma had been heavily criticized for failing to mobilize armed forces promptly. He waited three days to call a special national security meeting to mobilize troops and organize rescue and relief efforts in the affected areas. Unfortunately, international help was denied in the first few days. Many countries had stepped forward to provide rescue teams, equipment, and sanitation supplies but all were politely declined. International aid efforts were not mobilized until the Taiwanese cabinet reversed an earlier decision and said that it would accept foreign aid. The American's USS Denver arrived on August 17, 2009, a week after the storm hit. The navy ship brought heavy-lift helicopters that could carry the aid and equipment to remote mountain areas that were cut off by the typhoon (Taiwan's leader takes blame for typhoon response, 2009). More than 59 countries, including from the United States, Japan, Australia, New Zealand, Singapore, and Israel, made donations of emergency relief supplies.

Other international aid agencies involved in relief efforts included Taiwan Red Cross, Taiwan World Vision, and ShelterBox Response Teams, which contributed to the population's immediate needs (e.g., sleeping bags, blankets, food, and medicine) and helped with the recovery effort. The Taiwan Red Cross Organization mobilized 1,500 volunteers, in addition to providing non-food items from its disaster preparedness stocks. World 
Vision recruited over 1,000 volunteers to support aid distribution to affected families, care for children and the injured, and assist with the home clean-up effort as flood waters receded.

In addition, World Vision indicated they planned to invest over NT\$ 1.2 billion in emergency relief and rehabilitation programs for Typhoon Morakot (World Vision Taiwan typhoon Morakot relief response program highlights, 2009). The two leading relief agencies, World Vision Taiwan and Taiwan Red Cross also collaborated to help indigenous communities rebuild their homes and livelihood. The partnership of the two agencies ensured effective coordination and openly shared information to avoid duplication of work or the waste of resources.

Given the reliance on faith as a coping mechanism, research suggests that partnerships with religious institutions provide an avenue for reaching the public, especially among minority communities, recent immigrant communities, and the economically disadvantaged (Lachlan \& Spence, 2011). The religious volunteer groups including Christians, Catholics, Buddhists and Taoists are one of the distinctive features of Taiwan. Among them, Buddhist Tzu Chi Foundation provided various relief efforts, including home visits, disaster assessment, relief goods distribution, cleaning and free clinics during Typhoon Morakot. More than 200,000 Tzu Chi volunteers joined the relief work, and branches in 51 countries around the world launched fund-raising activities. As noted by Lachlan and Spence (2011), partnering with faith-based community organizations may engender more trust and improve effective communication. In the wake of Typhoon Morakot, the government's inefficient mobilization and coordination of relief efforts contrasted with the efficient and swift response of civilians, the private sectors, NGOs and faith-based groups.

\subsubsection{Lesson Four: Developing Culturally and Ethnically Competent Crisis Response}

While Seeger's (2006) ten best practices in crisis communication are identified to improve the way organizations can communicate effectively with the public during times of crisis, the transferability and applicability of these communication components across different cultures has yet to be fully explored. In this case, the key concern was the cultural and ethnic diversity of typhoon survivors. Many of the areas hardest hit by Typhoon Morakot were indigenous communities. In Taiwan, there are fourteen aboriginal tribes, with a combined population of 490,000 , approximately $2 \%$ of the total population. The Taiwanese aborigines belong to the Austronesian group and "they are more closely related to Southeast Asian island populations such as peoples of the Philippines, Malaysia, Indonesia, and Oceania" (Loa, 2007, p. 2). Many of these aboriginal people maintain a great deal of their indigenous socio-cultural heritage in their communities. However, they appear to suffer disproportionally from poverty, health and social problems (Wen, Tsai, Shih, \& Chung, 2004).

Government statistics show that nearly half of the Typhoon Morakot victims were aborigines (Shih \& Wang, 2009). When the government asked the survivors to evacuate, many aborigines preferred to stay in the village. In some cases they feared and worried that they might lose their lands permanently if evacuated. The villagers said: "once we have left our homes, we are no longer considered as residents, we become refugees" (Hu, 2009). Evacuation is a preferable option in the wake of natural disaster. According to a report, approximately $10 \%$ to $25 \%$ of an impacted population will not evacuate, even if ordered in a timely manner (Select Bipartisan Committee, 2006). Reasons may vary from lack of resources to evacuate, survival of similar events in the past or feeling lucky. Disaster studies have highlighted a tendency for minorities to be reluctant, or less likely to evacuate. Elliot and Pais (2006) point out, "individuals and families make sense of the threats posed by environmental hazards and respond to them in ways reflective of varying social and economic resources at their disposal" (p. 296). According to Gladwin and Peacock (1997), minorities may be at a disadvantage in terms of crisis preparedness because they are more likely to have lower incomes or be unemployed. They may live in more vulnerable areas and disaster-prone locations where they have no access transportation and fear leaving belongings behind.

In a crisis communication study, the scholars claim distrust of government by vulnerable populations including ethnic and racial minorities that may create an obstacle for preparation and evacuation messages (Spence, Lachlan, \& Griffin, 2007). Burby and Strong (1997) also suggest that minorities are more likely than others to indicate a distrust of institutions of government to protect their public health and safety. They may choose not to follow important public instructions because of their distrust of government instructions. In a visit to Typhoon Morakot survivors on August 31, 2009, President Ma tried to build trust and create awareness among the aboriginal people. He told his aboriginal audiences: "If we don't implement the mandatory evacuation, many people will call me incompetent and cold-blooded and blame me for causing so many to lose their lives...How can you not evacuate people when their lives are in danger? So I'm begging you, evacuate when it is necessary" (Ko, 2009b, p. 3).

After Typhoon Morakot, discussions on the reconstruction of aboriginal areas and relocation of villages also 
sparked debate. The aboriginal people who were evacuated were forced to settle in other areas isolated from their way of life and cultural heritage. In response to the accusation that relocation might jeopardize their culture, President Ma claimed "the government would not "wipe out" their villages and would respect the tradition, practices and cultures of the aborigines" (Ko, 2009b, p. 3). These factors illustrate the importance of considering culture in crisis response.

Reynolds and Seeger (2005) agree that messages are more effective if they match the audience's needs, values, background, culture and experience. In exploring this issue, Sellnow and Vidoloff (2009) shed new insights on the importance of acknowledging and accounting for cultural differences in the current best practices of crisis communication. Echoing their point of view, Liu and Pompper (2012) reinforce that "associated response strategies do not fully reflect the complexity of crises that involve issues of culture, ethnicity, and/or race" (p. 14) This study confirms that effective crisis communication requires both knowledge of people from other cultures and respect for their diversity. Overall, experience with aboriginal people in Typhoon Morakot underscore the need for better emergency communication plans for these populations through accessible channels.

\subsubsection{Lesson Five: Building a Community-Based Support System}

In addition to cultural and ethnic variables, government agencies need to work with the communities in the dissemination of public messages to audiences. In Taiwan, the disaster rescue and relief system can be divided into the central government and local government (county and township). The community management support system, however, has not yet been discussed. Considering the remote aboriginal tribes, the only access to the affected villages was by helicopter after the typhoon hit. Many of the villagers were trapped without drinking water and electricity. They were left homeless and isolated from their community network. Research shows that interpersonal networks are important during times of crisis, especially for minorities (Spence, Lachlan, \& Griffin, 2007). In this view, minorities are less likely to accept a warning message without confirmation from others close to them.

Accordingly, the message may be more effective if social networks are targeted, such as churches and community organizations. Cole and Fellows (2008) emphasize that "collaboration with community leaders should be established in the preparation of the disaster management plan" (p. 225). The increased connection in their communities may overcome distrust of the government and educate them on the effects of natural disaster and the importance of issues such as advanced preparation and evacuation. For example, the major religion of Taiwanese aborigines is Christian. Given their strong reliance on religious institutions, the Taiwanese government may use local churches to urge immediate evacuation and help for transportation. Building a community-based support system may have minimized the effects of disasters.

\section{Conclusion}

Typhoon Morakot was the worst typhoon to ever strike Taiwan. Typhoon Morakot crisis was a wake-up call for the Taiwanese government regarding its inadequate crisis management system. The typhoon brought three meters of rain, exceeding the island's average annual rainfall and causing huge floods and landslides. When compared to the government's response, the private sector's response was effective and swift. Many accusations were made that the government was unprepared and failed to respond promptly and effectively to the crisis. Although the government, especially local government, cannot be blamed for causing something as catastrophic as a typhoon, the public judge government response, in terms of how it handles the natural disaster. Understandably, however, citizens expect government to be actively involved in disaster preparation and response.

In general, the management of natural disasters has always included a significant communication component in the form of warnings, risk messages, evacuation notifications, messages regarding self-efficacy, information regarding resources and procedures, among many others (Reynolds \& Seeger, 2005). There was no doubt that the Taiwanese officials and agencies failed to embrace the risk and crisis communication discussed in this case. This is especially disconcerting since it is believed that Taiwan might suffer even more extreme weather conditions due to climate change. Seeger (2006) notes that all crises are unanticipated. The importance of disaster preparedness to reduce the impact of future natural disasters is necessary. In the past, the communication needs of minorities -- the most vulnerable population to natural disasters -- have received even less attention (Spence, Lachlan, \& Griffin, 2007). This study especially demonstrates the need for crisis prevention preparation among the at-risk vulnerable minority population. It is also important to note that community participation during reconstruction is essential. 


\section{References}

A president far from his people. (2009, August 12). Taipei Times, p. A8.

Abney, F. G., \& Hill, L. B. (1966). Natural disasters as a political variable: The effect of a hurricane on an urban election. The American Political Science Review, 60, 974-981. http://dx.doi.org/10.2307/1953770

Adams, J. (2009, August 18). Taiwan president under fire over typhoon response. The Christian Science Monitor. Retrieved February 1, 2012, from http://www.csmonitor.com/World/Asia-Pacific/2009/0818/p06s01-woap.html

Avery, E. J., \& Lariscy, R. W. (2010). FEMA and the rhetoric of redemption: New directions in crisis communication models for government agencies. In W. T. Coombs, \& Holladay (Eds.), The Handbook of Crisis Communication (pp. 319-334). Thousand Oaks, CA: Sage Publications.

Benoit, W. L. (1995). Accounts, excuses, and apologies: A theory of image restoration strategies. Albany: State University of New York Press.

Braun, V., \& Clarke, V. (2006). Using thematic analysis in psychology. Qualitative Research in Psychology, 3(2), 77-101. http://dx.doi.org/10.1191/1478088706qp063oa

Burby, R., \& Strong, D. (1997). Coping with chemicals: Blacks, Whites, planners, and industrial pollution. Journal of American Planning Association, 63, 469-480. http://dx.doi.org/10.1080/01944369708975940

Chung, L. (2009, August 19). Political storm clouds gather around Ma: First ministerial casualty as fury grows at official response to Typhoon Morakot. South China Morning Post, p. A4.

Cole, T. W., \& Fellows, K. L. (2008). Risk communication failure: A case study of New Orleans and Hurricane Katrina. Southern Communication Journal, 73(3), 211-228. http://dx.doi.org/10.1080/10417940802219702

Comfort, L. K. (1989). The San Salvador earthquake. In U. Rosenthal, M. T. Charles, \& P. T. Hart (Eds.), Coping with crises (pp. 321-339). Springfield, IL: Charles C. Thomas.

Comfort, L. K., Sungu, Y., Johnson, D., \& Dunn, M. (2001). Complex systems in crisis: Anticipation and resilience in dynamic environments. Journal of Contingencies and Crisis Management, 9(3), 144-158. http://dx.doi.org/ 10.1111/1468-5973.00164

Coombs, W. T. (1999). Information and compassion in crisis responses: A test of their effects. Journal of Public Relations, 11(2), 125-142. http://dx.doi.org/10.1207/s1532754xjprr1102_02

Coombs, W. T. (2007). Ongoing crisis communication: Planning, managing, and responding (2nd ed.). Thousand Oaks, CA: Sage Publications.

Coombs, W. T. (2009). Conceptualizing crisis communication. In R. Heath, \& H. D. O'Hair (Eds.), Handbook of risk and crisis communication (pp. 88-118). New York: Routledge.

Dozier, D. M., \& Broom, G. M. (1995). Evolution of the managerial role in public relations practice. Journal of Public Relations Research, 7(1), 3-36. http://dx.doi.org/10.1207/s1532754xjprr0701_02

Elliott, J. R., \& Pais, J. (2006). Race, class and Hurricane Katrina: Social differences in human responses to disaster. Social Science Research, 35, 295-321. http://dx.doi.org/10.1016/j.ssresearch.2006.02.003

Enav, P. (2009, August 14). Taiwan's president criticized for typhoon response. Associated Press Online. Retrieved February 4, 2012, from Lexis Nexis Academic Universe.

Fearn-Banks, K. (2010). Crisis communications: A casebook approach (4th ed.). Mahwah, NJ: Lawrence Erlbaum Associates, Inc.

Fink, S. (1986). Crisis management: Planning for the inevitable. New York: AMACOM.

Gallagher, A. H., Fontenot, M., \& Boyle, K. (2007). Communicating during times of crises: An analysis of news releases from the federal government before, during, and after hurricanes Katrina and Rita. Public Relations Review, 33, 217-219. http://dx.doi.org/10.1016/j.pubrev.2007.02.009

Garnett, J., \& Kouzmin, A. (2007). Communicating throughout Katrina: Competing and complementary conceptual lenses on crisis communication. Public Administration Review, 67(S1), 171-188. http://dx.doi.org/10.1111/j.1540-6210.2007.00826.x

Gladwin, H., \& Peacock, W. G. (1997). Warning and evacuation: A night for hard houses. In W. G. Peacock, B. H. Morrow, \& H. Gladwin (Eds.), Hurricane Andrew: Ethnicity, gender and sociology of disasters (pp. 52-74). London: Routledge. 
Hale, J. E., Dulek, R. E., \& Hale, D. P. (2005). Crisis response communication challenges. Journal of Business Communication, 42(2), 112-134. http://dx.doi.org/10.1177/0021943605274751

Ho, A. L. (2009, August 27). Ma's image takes a battering from Typhoon Morakot: Inability to act quickly and flexibly has marred his reputation. The Straits Times. Retrieved February 2, 2012, from Lexis Nexis Academic Universe.

Ho, F., \& Hallahan, K. (2004). Post-earthquake crisis communications in Taiwan: An examination of corporate advertising and strategy motives. Journal of Communication Management, 8(3), 291-306. http://dx.doi.org/10.1108/13632540410807709

Hsu, J. W. (2009, August 16). Morakot: The aftermath, foreign aid pours in after Taiwan eases restrictions. Taipei Times, p. A3.

Hsu, J. W., \& Wang, F. (2009, August 15). Morakot: The aftermath, MOFA sorry, but denies mistake over refusing aid. Taipei Times, p. A1.

Hu, M. (2009, August 17). Don't want to be called refugees. Lih Pao. Retrieved February 15, 2012, from http://www.lihpao.com/?action-viewnews-itemid-14270

Jacobs, A. (2009, August 14). Death Toll Is Still Rising After Storm in Taiwan. The New York Times. Retrieved February 1, 2012, from http://www.nytimes.com/2009/08/15/world/asia/15taiwan.html

Kao, Y. L. (2009). National advisor offers to resign after making damaging remarks. Central News Agency. Retrieved December 1, 2011, from Lexis Nexis Academic Universe.

Ko, S. (2009a, August 20). Morakot: The Aftermath, Ma, Liu approval ratings plummet in Morakot's wake. Taipei Times, p. A1.

Ko, S. (2009b, August 31). Evacuations will be necessary, Ma says. Taipei Times, p. A3.

Lachlan, K. A., \& Spence, P. R. (2011). Crisis communication and the underserved: The case for partnering with institutions of faith. Journal of Applied Communication Research, 39(4), 448-451. http://dx.doi.org/10.1080/00909882.2011.608692

Lerbinger, O. (1997). The crisis manager: Facing risk and responsibility. Mahwah, NJ: Lawrence Erlbaum.

Littlefield, R. S., \& Cowden, K. J. (2006). Rethinking the single spokesperson model of crisis communication: Recognizing the need to address multiple publics. Paper presented at the annual convention of National Communication Association, San Antonio, TX, USA.

Littlefield, R. S., \& Quenette, A. M. (2007). Crisis leadership and Hurricane Katrina: The portrayal of authority by the media in natural disasters. Journal of Applied Communication Research, 35(1), 26-47. http://dx.doi.org/10.1080/00909880601065664

Liu, B. F., \& Pompper, D. (2012). The crisis with no name: Defining the interplay of culture, ethnicity, and race on organizational issues and media outcomes. Journal of Applied Communication Research, 40, 1-20. http://dx.doi.org/10.1080/00909882.2012.654499

Loa, I. (2007, October 30). Researchers back theory on Austronesian origins. Taipei Times, p. A2.

Ma Ying-jeou's Katrina moment: The political storm of Typhoon Morakot. (2009, August 17). Wall Street Journal. Retrieved $\quad$ February $1, \quad$ 2012, from http://online.wsj.com/article/SB100014240529702046832045743555691015919658.html\#articleTabs\%3Dart icle

Marshal, S. (1986). NASA after Challenger: The public affairs perspective. The Public Relations Journal, 42(8), $17-23$.

Office of the President. (2009a). President Ma visits central emergency operation center for fifth time. [Press release]. Retrieved from http://english.president.gov.tw/Default.aspx?tabid=491\&itemid=19480\&rmid=2355\&word1 =morakot

Office of the President. (2009b). President Ma's opening remarks at foreign news conference. [Press release]. Retrieved

from

http://english.president.gov.tw/Default.aspx?tabid=491\&itemid=19487\&rmid=2355\&word1 =morakot

Perrow, C. (1999). Normal accidents: Living with high-risk technologies. Princeton, NJ: Princeton University Press. 
Perry, S. D. (2007). Tsunami warning dissemination in Mauritius. Journal of Applied Communication Research, 35(4), 399-417. http://dx.doi.org/10.1080/00909880701611060

Pinsdorf, M. (2004). All crises are global: Managing to escape chaos. New York: Fordham University Press.

Reshuffling the cabinet is not enough. (2009, August 23). The China Post. Retrieved December 9, 2011, from http://www.chinapost.com.tw/editorial/taiwan- issues/2009/08/23/221655/Reshuffling-the.htm

Reynolds, B. (2006). Response to best practices. Journal of Applied Communication Research, 34(3), $249-252$. http://dx.doi.org/10.1080/00909880600771593

Reynolds, B., \& Seeger, M. W. (2005). Crisis and emergency risk communication as an integrative model. Journal of Health Communication, 10, 43-55. http://dx.doi.org/10.1080/10810730590904571

Seeger, M. (2006). Best practices in crisis communication: An expert panel process. Journal of Applied Communication Research, 34, 232-244. http://dx.doi.org/10.1080/00909880600769944

Seeger, M. W., \& Ulmer, R. R. (2002). A post-crisis discourse of renewal: The cases of Malden Mills and Cole Hardwoods. Journal of Applied Communication Research, 30, $126-142$. http://dx.doi.org/10.1080/00909880216578

Seeger, M. W., Sellnow, T. L., \& Ulmer, R. R. (2003). Communication and organizational crisis. Westport, CT: Praeger.

Select Bipartisan Committee. (2006, February 15). A failure of initiative: Final report of the select bipartisan committee to investigate the preparation for and response to Hurricane Katrina. 109th Congress, 2nd Session, U.S. Government Printing Office.

Sellnow, T. L., \& Vidoloff, K. G. (2009). Getting communication right. Food Technology, 63(9). Retrieved February 17, 2012, from http:/www.ift.org

Sellnow, T. L., Seeger, M. W., \& Ulmer, R. R. (2002). Chaos theory, informational needs, and natural disasters. Journal of Applied Communication Research, 30(4), 269-292. http://dx.doi.org/10.1080/00909880216599

Sellnow, T. L., Ulmer, R. R., Seeger, M. W., \& Littlefield, R. S. (2009). Effective risk communication: A message-centered approach. New York: Springer. http://dx.doi.org/10.1007/978-0-387-79727-4

Seo, H., Kim, J. Y., \& Yang, S. U. (2009). Global activism and new media: A study of transnational NGO's online public relations. Public Relations Review, 35(2), 123-126. http://dx.doi.org/10.1016/j.pubrev.2009.02.002

Shen, S. (2009, August 21). Typhoon response costs Taiwan's leaders. UPI. Retrieved February 2, 2012, from Lexis Nexis Academic Universe.

Shih, H., \& Wang, F. (2009, August 27). Liu seeks input from aboriginal heads. Taipei Times, p. A3.

Spence, P. R., Lachlan, K. A., \& Griffin, D. R. (2007). Crisis communication, race, and natural disasters. Journal of Black Studies, 37(4), 539-553. http://dx.doi.org/10.1177/0021934706296192

Taiwan needs to create its own FEMA. (2009, August 18). The China Post. Retrieve February 5, 2012, from http://www.chinapost.com.tw/editorial/taiwan- issues/2009/08/18/220882/p2/Taiwan-needs.htm

Taiwan's leader takes blame for typhoon response. (2009, August 17). CNN. Retrieved February 4, 2012, from http://edition.cnn.com/2009/WORLD/asiapcf/08/16/taiwan.president.typhoon/index.html?iref=allsearch

Typhoon highlights old inefficiencies. (2009, August 10). Taipei Times, p. A8.

Typhoon Morakot nears Taiwan. (2009, August 6). CNN. Retrieved September 25, 2011, from http:/edition.cnn.com/2009/WORLD/weather/08/06/typhoon.morakot.taiwan/

Typhoon Morakot was painful lesson. (2010, August 9). The China Post. Retrieved October 27, 2011, from http://www.chinapost.com.tw/taiwan/national/national-news/2010/08/09/267923/Typhoon-Morakot.htm

Ulmer, R. R., Sellnow, T. L., \& Seeger, M. W. (2007). Effective crisis communication: Moving from crisis to opportunity. Thousand Oaks, CA: Sage Publications.

Veil, S. R., Buehner, T., \& Palenchar, M. J. (2011). A work-in-process literature review: Incorporating social media in risk and crisis communication. Journal of Contingencies and Crisis Management, 19(2), 110-122. http://dx.doi.org/10.1111/j.1468-5973.2011.00639.x

Venette, S. J. (2006). Special section introduction: Best practices in risk and crisis communication. Journal of Applied Communication Research, 34(3), 229-231. http://dx.doi.org/10.1080/00909880600769464 
Voters don't realize the good work Liu Chao-shiuan has done. (2010, May 27). The China Post. Retrieved February 2 , 2012 , from http://www.chinapost.com.tw/editorial/taiwan-issues/2010/05/27/258081/Voters-dont.htm

Waymer, D., \& Heath, R. (2007). Emergent agents: The forgotten publics in crisis communication and issues management research. Journal of Applied Communication Research, 35(1), 88-108. http://dx.doi.org/10.1080/00909880601065730

Wen, C., Tsai, S., Shih, Y., \& Chung, W. (2004). Bridging the gap in life expectancy of the aborigines in Taiwan. International Journal of Epidemiology, 33, 320-327. http://dx.doi.org/10.1093/ije/dyh009

World Vision Taiwan typhoon Morakot relief response program highlights. (2009, August 25). World Vision Latest News. Retrieved April 6, 2011, from http://www.worldvision.org.tw/en/news-090825.htm

Wu, S. (2009 a, September 16). Prevention better than cure in natural disaster response: president. Central News Agency. Retrieved December 6, 2011, from Lexis Nexis Academic Universe.

Wu, S. (2009b, September 19). Executive Yuan secretary-general, defense minister offer to resign. Central News Agency. Retrieved December 6, 2011, from Lexis Nexis Academic Universe. 